\title{
Training Residents in Hospital Medicine: The Hospitalist Elective National Survey
}

\author{
Steven Ludwin, MD*, James D. Harrison, MPH, PhD1', Sumant Ranji, MD², Bradley A. Sharpe, MD¹, Patrick Kneeland, MD³
}

'Department of Medicine, Division of Hospital Medicine, University of California, San Francisco, California; ${ }^{2}$ Department of Medicine, Division of Hospital Medicine at Zuckerberg San Francisco General Hospital, University of California, San Francisco, California; ${ }^{3}$ Department of Medicine, University of Colorado School of Medicine, Aurora, Colorado.

As the field of hospital medicine expands, internal medicine residency programs can play a role in preparing future hospitalists. To date, little is known of the prevalence and characteristics of hospitalist-focused resident rotations. We surveyed the largest 100 Internal Medicine Residency Programs to better understand the prevalence, objectives, and structure of hospitalist-focused rotations in the United States. Residency leaders from 82 programs responded (82\%). The prevalence of hospitalist-focused rotations was $50 \%(41 / 82)$ with an additional 9 programs (11\%) planning to start one. Of these 41 rotations, $85 \%$ were elective rotations and $15 \%$ were mandatory rotations. Rotations involved clinical responsibilities, and most programs incorporated nonclinical curricular activities such as teaching, research, and work on quality improvement and patient safety. Respondents noted that their programs promoted autonomy, mentorship, and "real-world" hospitalist experience. Hospitalist-focused rotations may supplement traditional inpatient rotations and teach skills that facilitate the transition from residency to a career in hospital medicine. Journal of Hospital Medicine 2018;13: 623-625. Published online first March 26, 2018. (C) 2018 Society of Hospital Medicine

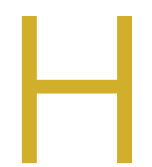

ospital medicine has become the fastest growing medicine subspecialty, though no standardized hospitalist-focused educational program is required to become a practicing adult medicine hospitalist. ${ }^{1} \mathrm{His}$ torically, adult hospitalists have had little additional training beyond residency, yet, as residency training adapts to duty hour restrictions, patient caps, and increasing attending oversight, it is not clear if traditional rotations and curricula provide adequate preparation for independent practice as an adult hospitalist. ${ }^{2-5}$ Several types of training and educational programs have emerged to fill this potential gap. These include hospital medicine fellowships, residency pathways, early career faculty development programs (eg, Society of Hospital Medicine/ Society of General Internal Medicine sponsored Academic Hospitalist Academy), and hospitalist-focused resident rotations. ${ }^{6-10}$ These activities are intended to ensure that residents and early career physicians gain the skills and competencies required to effectively practice hospital medicine.

Hospital medicine fellowships, residency pathways, and faculty development have been described previously. ${ }^{6-8}$ However, the prevalence and characteristics of hospital medicine-fo-

\footnotetext{
*Address for correspondence: Steven Ludwin, MD, Assistant Professor of Medicine, Division of Hospital Medicine, University of California, San Francisco, 533 Parnassus Avenue, Box 0131, San Francisco, CA 94113; Telephone: 415-4764814; Fax: 415-502-1963; E-mail: Steven.Ludwin@ucsf.edu

Additional Supporting Information may be found in the online version of this article.
}

Received: August 25, 2017; Revised: November 13, 2017; Accepted: November 14, 2017

๑ 2018 Society of Hospital Medicine DOI 10.12788/jhm.2952 cused resident rotations are unknown, and these rotations are rarely publicized beyond local residency programs. Our study aims to determine the prevalence, purpose, and function of hospitalist-focused rotations within residency programs and explore the role these rotations have in preparing residents for a career in hospital medicine.

\section{METHODS}

\section{Study Design, Setting, and Participants}

We conducted a cross-sectional study involving the largest 100 Accreditation Council for Graduate Medical Education (ACGME) internal medicine residency programs. We chose the largest programs as we hypothesized that these programs would be most likely to have the infrastructure to support hospital medicine focused rotations compared to smaller programs. The UCSF Committee on Human Research approved this study.

\section{Survey Development}

We developed a study-specific survey (the Hospitalist Elective National Survey [HENS]) to assess the prevalence, structure, curricular goals, and perceived benefits of distinct hospitalist rotations as defined by individual resident programs. The survey prompted respondents to consider a "hospitalist-focused" rotation as one that is different from a traditional inpatient "ward" rotation and whose emphasis is on hospitalist-specific training, clinical skills, or career development. The 18-question survey (Appendix 1) included fixed choice, multiple choice, and open-ended responses.

\section{Data Collection}

Using publicly available data from the ACGME website (www. acgme.org), we identified the largest 100 medicine programs 
TABLE 1. Activities and Curricular Elements of Hospital Medicine-Specific Rotations ( $n=41$ )

\begin{tabular}{|c|c|}
\hline & $\mathrm{n}(\%)$ \\
\hline \multicolumn{2}{|l|}{ Clinical activities } \\
\hline See medicine consults & $13(32)$ \\
\hline Comanage patients on non-medicine services & $16(39)$ \\
\hline Take holdover admissions & $19(46)$ \\
\hline Admit new patients (not holdovers) & $29(71)$ \\
\hline Perform common IM procedures & $17(41)$ \\
\hline Work off site at SNF or post acute care & $4(10)$ \\
\hline \multicolumn{2}{|l|}{ Non-clinical activities } \\
\hline Teach students & $7(17)$ \\
\hline Teach house staff & $3(7)$ \\
\hline Engage in research and scholarship & $5(12)$ \\
\hline Work on QI and patient safety & $15(37)$ \\
\hline Other & $15(37)$ \\
\hline \multicolumn{2}{|l|}{ Curricular elements } \\
\hline Evidence-based practice in hospital medicine & $20(49)$ \\
\hline Career mentorship & $20(49)$ \\
\hline Quality improvement & $20(49)$ \\
\hline Patient safety & $15(37)$ \\
\hline Patient satisfaction & $3(7)$ \\
\hline Healthcare finances & $2(5)$ \\
\hline Leadership development & $3(7)$ \\
\hline Value in healthcare & $11(27)$ \\
\hline Billing and compliance & $19(46)$ \\
\hline Palliative and end-of-life care & $3(7)$ \\
\hline
\end{tabular}

Abbreviations: IM, internal medicine, QI, quality improvement, SNF, skilled nursing facility

based on the total number of residents. This included programs with 81 or more residents. An electronic survey was e-mailed to the leadership of each program. In May 2015, surveys were sent to Residency Program Directors (PD), and if they did not respond after 2 attempts, then Associate Program Directors (APD) were contacted twice. If both these leaders did not respond, then the survey was sent to residency program administrators or Hospital Medicine Division Chiefs. Only one survey was completed per site.

\section{Data Analysis}

We used descriptive statistics to summarize quantitative data. Responses to open-ended qualitative questions about the goals, strengths, and design of rotations were analyzed using thematic analysis. ${ }^{11}$ During analysis, we iteratively developed and refined codes that identified important concepts that emerged from the data. Two members of the research team trained in qualitative data analysis coded these data independently (S.L. and J.H.).

\section{RESULTS}

Eighty-two residency program leaders (53 PD, 19 APD, 10 chiefs/admin) responded to the survey (82\% total response rate). Among all responders, the prevalence of hospitalist-focused rotations was 50\% (41/82). Of these 41 rotations, $85 \%$ (35/41) were elective rotations and 15\% (6/41) were mandatory rotations. Hospitalist rotations ranged in existence from 1 to 15 years with a mean duration of 4.78 years (S.D. 3.5).

Of the 41 programs that did not have a hospital medicine-focused rotation, the key barriers identified were a lack of a well-defined model (29\%), low faculty interest (15\%), low resident interest (12\%), and lack of funding (5\%). Despite these barriers, 9 of these 41 programs (22\%) stated they planned to start a rotation in the future - of which, 3 programs $(7 \%)$ planned to start a rotation within the year.

Of the 41 established rotations, most were one month in duration (31/41, 76\%) and most of the participants included second-year residents (30/41,73\%), and/or third-year residents (32/41, 78\%). In addition to clinical work, most rotations had a nonclinical component that included teaching, research/scholarship, and/or work on quality improvement or patient safety (Table 1). Clinical activities, nonclinical activities, and curricular elements varied across institutions (Table 1).

Most programs with rotations (39/41, 95\%) reported that their hospitalist rotation filled at least one gap in traditional residency curriculum. The most frequently identified gaps the rotation filled included: allowing progressive clinical autonomy $(59 \%, 24 / 41)$, learning about quality improvement and high value care $(41 \%, 17 / 41)$, and preparing to become a practicing hospitalist $(39 \%, 16 / 41)$. Most respondents $(66 \%, 27 / 41)$ reported that the rotation helped to prepare trainees for their first year as an attending.

Results of thematic analysis related to the goals, strengths, and design of rotations are shown in Table 2. Five themes emerged relating to autonomy, mentorship, hospitalist skills, real-world experience, and training and curriculum gaps. These themes describe the underlying structure in which these rotations promote career preparation and skill development.

\section{DISCUSSION}

The Hospital Elective National Survey provides insight into a growing component of hospitalist-focused training and preparation. Fifty percent of ACGME residency programs surveyed in this study had a hospitalist-focused rotation. Rotation characteristics were heterogeneous, perhaps reflecting both the homegrown nature of their development and the lack of national study or data to guide what constitutes an "ideal" rotation. Common functions of rotations included providing career mentorship and allowing for trainees to get experience "being a hospitalist." Other key elements of the rotations included providing additional clinical autonomy and teaching material outside of traditional residency curricula such as quality improvement, patient safety, billing, and healthcare finances.

Prior research has explored other training for hospitalists such as fellowships, pathways, and faculty development..-8 A hospital medicine fellowship provides extensive training but without a practice requirement in adult medicine (as now exists in pediatric hospital medicine), the impact of fellowship training may be limited by its scale. ${ }^{12,13}$ Longitudinal hospitalist residency 
TABLE 2: Results of Thematic Analysis Describing Goals, Strengths, and Design of Rotations

\begin{tabular}{ll}
\hline Theme & Representative quotes \\
\hline Autonomy & "No team...resident works one-on-one with a hospitalist doing direct patient care. More resident autonomy" \\
& "Autonomy, opportunity to direct patient care responsibility" \\
\hline Mentorship & "One-on-one mentorship for QI projects with experienced academic hospitalists" \\
\hline "Work directly one-on-one with a hospitalist attending with focused curriculum..." & "Gives residents greater exposure to consultative medicine and comanagement of patients with physicians, mid-level practitioners, pharmacy, therapists, etc." \\
\hline "Eills training and curricula gaps & "Concentration on Ql, patient safety, and project leadership skills" \\
\hline "Increases patient management skills, specifically in the entire spectrum from admission all the way to discharge. Increases focus of discharge planning" & "Job 'try-out' - in other words, residents get to see if they like the hospitalist model" \\
\hline "Real-world hospital medicine experience, time and opportunities for quality improvement/patient safety projects"
\end{tabular}

pathways provide comprehensive skill development and often require an early career commitment from trainees. ${ }^{7}$ Faculty development can be another tool to foster career growth, though requires local investment from hospitalist groups that may not have the resources or experience to support this. ${ }^{8}$ Our study has highlighted that hospitalist-focused rotations within residency programs can train physicians for a career in hospital medicine. Hospitalist and residency leaders should consider that these rotations might be the only hospital medicine-focused training that new hospitalists will have. Given the variable nature of these rotations nationally, developing standards around core hospitalist competencies within these rotations should be a key component to career preparation and a goal for the field at large..$^{14,15}$

Our study has limitations. The survey focused only on internal medicine as it is the most common training background of hospitalists; however, the field has grown to include other specialties including pediatrics, neurology, family medicine, and surgery. In addition, the survey reviewed the largest ACGME Internal Medicine programs to best evaluate prevalence and content-it may be that some smaller programs have ro-

\section{References}

1. Wachter RM, Goldman L. Zero to 50,000 - The $20^{\text {th }}$ Anniversary of the Hospitalist. N Engl J Med. 2016;375:1009-1011.

2. Glasheen JJ, Siegal EM, Epstein K, Kutner J, Prochazka AV. Fulfilling the promise of hospital medicine: tailoring internal medicine training to address hospitalists' needs. J Gen Intern Med. 2008;23:1110-1115.

3. Glasheen JJ, Goldenberg J, Nelson JR. Achieving hospital medicine's promise through internal medicine residency redesign. Mt Sinai J Med. 2008; 5:436-441.

4. Plauth WH 3rd, Pantilat SZ, Wachter RM, Fenton CL. Hospitalists' perceptions of their residency training needs: results of a national survey. Am J Med. 2001; 15;111:247-254.

5. Kumar A, Smeraglio A, Witteles R, Harman S, Nallamshetty, S, Rogers A, Harrington $R$, Ahuja N. A resident-created hospitalist curriculum for internal medicine housestaff. J Hosp Med. 2016;11:646-649.

6. Ranji, SR, Rosenman, DJ, Amin, AN, Kripalani, S. Hospital medicine fellowships: works in progress. Am J Med. 2006;119(1):72.e1-7.

7. Sweigart JR, Tad-Y D, Kneeland P, Williams MV, Glasheen JJ. Hospital medicine resident training tracks: developing the hospital medicine pipeline. $J$ Hosp Med. 2017;12:173-176.

8. Sehgal NL, Sharpe BA, Auerbach AA, Wachter RM. Investing in the future: tations with different characteristics that we have not captured. Lastly, the survey reviewed the rotations through the lens of residency program leadership and not trainees. A future survey of trainees or early career hospitalists who participated in these rotations could provide a better understanding of their achievements and effectiveness.

\section{CONCLUSION}

We anticipate that the demand for hospitalist-focused training will continue to grow as more residents in training seek to enter the specialty. Hospitalist and residency program leaders have an opportunity within residency training programs to build new or further develop existing hospital medicine-focused rotations. The HENS survey demonstrates that hospitalist-focused rotations are prevalent in residency education and have the potential to play an important role in hospitalist training.

Disclosure: The authors declare no conflicts of interest in relation to this manuscript.

building an academic hospitalist faculty development program. J Hosp Med. 2011;6:161-166.

9. Academic Hospitalist Academy. Course Description, Objectives and Society Sponsorship. Available at: https://academichospitalist.org/. Accessed August 23, 2017.

10. Amin AN. A successful hospitalist rotation for senior medicine residents. Med Educ. 2003;37:1042.

11. Braun V, Clarke V. Using thematic analysis in psychology. Qual Res Psychol. 2006;3:77-101.

12. American Board of Medical Specialties. ABMS Officially Recognizes Pediatric Hospital Medicine Subspecialty Certification Available at: http://www. abms.org/news-events/abms-officially-recognizes-pediatric-hospital-medicine-subspecialty-certification/. Accessed August 23, 2017.

13. Wiese J. Residency training: beginning with the end in mind. J Gen Intern Med. 2008; 23(7):1122-1123.

14. Dressler DD, Pistoria MJ, Budnitz TL, McKean SC, Amin AN. Core competencies in hospital medicine: development and methodology. $\mathrm{J}$ Hosp Med. 2006; 1 Suppl 1:48-56.

15. Nichani S, Crocker J, Fitterman N, Lukela M. Updating the core competencies in hospital medicine -2017 revision: introduction and methodology. $J$ Hosp Med. 2017;4:283-287. 